\title{
A generalized one-step in situ formation of metal sulfide/reduced graphene oxide nanosheets toward high-performance supercapacitors
}

\author{
Kaiyang Zhang ${ }^{1 \dagger}$, Yuanhao Wei ${ }^{1 \dagger}$, Jun Huang ${ }^{1}$, Yingbo Xiao ${ }^{1}$, Weizu Yang ${ }^{1}$, Ting $\mathrm{Hu}^{3}$, \\ Kai Yuan ${ }^{1 *}$ and Yiwang Chen ${ }^{1,2^{*}}$
}

\begin{abstract}
Metal sulfides are promising candidates for supercapacitors, but their slow reaction kinetics hinders their electrochemical performance. Large electrochemical surface area and combination with conductive carbon are potential methods to improve their capacitive performance. However, seeking for a generalized and simple approach to prepare twodimensional composites of metal sulfide and conductive carbon for supercapacitors is challengeable. Herein, a generalized and facile one-step pyrolysis method was designed for in situ growth of cobalt nickel sulfides $\left(\mathrm{CoNi}_{2} \mathrm{~S}_{4}\right)$ on reduced graphene oxide (rGO) nanosheets $\left(\mathrm{CoNi}_{2} \mathrm{~S}_{4} / \mathrm{rGO}\right)$ under mild conditions. The as-prepared $\mathrm{CoNi}_{2} \mathrm{~S}_{4} / \mathrm{rGO}$ materials possess the nanoparticleson-nanosheets structure, which is effective to provide a myriad of active sites and optimized electron/ion diffusion pathway. Benefiting from those advantages, the resultant $\mathrm{CoNi}_{2} \mathrm{~S}_{4} / \mathrm{rGO}$ electrodes exhibit impressed specific capacitances of 1526 and $988 \mathrm{~F} \mathrm{~g}^{-1}$ at 2 and $20 \mathrm{~A} \mathrm{~g}^{-1}$, respectively. The supercapacitors based on $\mathrm{CoNi}_{2} \mathrm{~S}_{4} / \mathrm{rGO}$ showcase an operation potential window of $1.6 \mathrm{~V}$, and energy density of $54.8 \mathrm{~W} \mathrm{~h} \mathrm{~kg}^{-1}$ at the power density of $798 \mathrm{~W} \mathrm{~kg}^{-1}$. The capacitance retention of the supercapacitor is about $93.7 \%$ after 8000 cycles at $3 \mathrm{~A} \mathrm{~g}^{-1}$. Moreover, a series of metal sulfide/rGO hybrids are obtained by this generalized strategy, which could be extended to construct electrode materials for various energy devices.
\end{abstract}

Keywords: metal sulfide, reduced graphene oxide, in situ growth, two-dimensional, supercapacitors

\section{INTRODUCTION}

Developing sustainable energy resources is one of the significant channels to meet the challenge of fossil fuel overconsumption [1-4]. Supercapacitors (SCs) have attracted extensive attentions due to their special advantages including high security, low cost, high power density and long discharging/charging cycles [5-8]. However, the feature of low energy density restricts further development of SCs [9-11]. Adopting high capacitance materials is an effective way to expanding energy density of SCs according to the equation $E=0.5 C V^{2}$, where $C$ and $V$ are the specific capacitance and voltage window of the devices, respectively [12-14]. Transitional metal sulfides possess higher capacitance than their oxide counterparts because of the lower electronegativity of sulfur, rendering them promising candidates for SCs [15-17]. Especially, mixed metal sulfides such as $\mathrm{NiCo}_{2} \mathrm{~S}_{4}$ [18-20], $\mathrm{MnCo}_{2} \mathrm{~S}_{4}$ [21], $\mathrm{CuCo}_{2} \mathrm{~S}_{4}$ [22] possess much more significant electrochemical activity and specific capacitance in contrast to single-metallic sulfides because of the synergistic effect among different components $[23,24]$.

Ternary nickel cobalt sulfides (NCSs), a typical class of electrode materials, have been extensively investigated in the field of SCs [25]. Although NCS is a kind of promising material for SCs, it suffers low electronic conductivity and unstable volume expansion. As a result, the diffusion of electron/ion through the materials will be retarded and the energy density will be further reduced [26]. One way to boost the electron/ion diffusion is adopting rational nanostructural design for advanced NCS electrodes, which can enhance the electrical con-

\footnotetext{
${ }^{1}$ Institute of Polymers and Energy Chemistry, College of Chemistry, Nanchang University, Nanchang 330031, China

${ }^{2}$ Institute of Advanced Scientific Research (iASR), Jiangxi Normal University, Nanchang 330022, China

${ }^{3}$ School of Materials Science and Engineering, Nanchang University, Nanchang 330031, China

${ }^{\dagger}$ These authors contributed equally to this paper.

* Corresponding authors (emails: kai.yuan@ncu.edu.cn (Yuan K); ywchen@ncu.edu.cn (Chen Y))
} 
ductivity and shorten the electron/ion diffusion path [27]. As a consequence, NCSs with various nanostructures like nanosheets [28], nanotubes [29], nanoparticles [30], have been frequently applied as positive electrode materials in the field of SCs. In particular, NCS nanoparticles have attracted much attention because the nanoparticle structure owns larger electrochemical surface area [31]. However, the applications of NCS nanoparticles were restricted due to the serious aggregation during the preparation and practical application processes. Therefore, the electrochemical performance significantly shrank, as well as showed poor cyclic stability and inferior rate performance attributed to the sluggish electron/ion transfer kinetics [32]. To address this obstacle, an effective approach is introducing carbon substrate to simultaneously enhance the conductivity and well distribute the NCS nanoparticles [33].

Two-dimensional (2D) graphene oxide (GO) is commonly employed as a template for planar growth of metal sulfides [34,35]. The metal sulfide precursors could gather on the surface of GO via strong interactions between the precursors and the abundant oxygenated functional groups on the surface of GO [36,37]. After heating treatment, the conductivity of GO will be enhanced because the oxygenated functional groups are partially reduced to form thermal reduced GO (rGO). Therefore, GO as an eminent support for transition metal sulfide nanoparticles is extensively applied to SCs. Most recently, many studies have been devoted to the preparation of metal sulfide/rGO composites [38-43]. Nevertheless, most of approaches are restricted by the following intrinsic limitations: i) as the precursors do not contain sulfur element, the introduction of other sulfur sources like thioacetamide (TAA) or $\mathrm{Na}_{2} \mathrm{~S}$ is indispensable. ii) The reactions need to be carried out under harsh conditions, such as electrodeposition, and hydrothermal condition. iii) The synthetic procedure is usually complex. It is still a challenge to prepare $2 \mathrm{D}$ composite materials based on metal sulfide/rGO by the one-step method under mild conditions.

Herein, we present a facile one-step pyrolysis method for the preparation of $\mathrm{CoNi}_{2} \mathrm{~S}_{4} / \mathrm{rGO}$ hybrids by in situ growth of homogeneously dispersed $\mathrm{CoNi}_{2} \mathrm{~S}_{4}$ nanoparticles on rGO nanosheets under mild conditions. The metal ethylxanthate deposited on GO nanosheets was used as the precursor for the formation of metal sulfide/ rGO hybrids. The distribution of the $\mathrm{CoNi}_{2} \mathrm{~S}_{4}$ nanoparticles can be regulated by adjusting the contents of GO. As a universal method, various metal sulfide/rGO hybrids with different morphologies can be prepared successfully. Reviewed in a three-electrode configuration, the as-prepared $\mathrm{CoNi}_{2} \mathrm{~S}_{4} / \mathrm{rGO}$ hybrids show high specific capacitance of $1526 \mathrm{~F} \mathrm{~g}^{-1}$ at $2 \mathrm{~A} \mathrm{~g}^{-1}$. More prominently, an asymmetric supercapacitor (ASC) was fabricated with $\mathrm{CoNi}_{2} \mathrm{~S}_{4} / \mathrm{rGO}$ as the positive electrode and active carbon (AC) as the negative electrode, achieving a high energy density of $54.8 \mathrm{~W} \mathrm{~h} \mathrm{~kg}^{-1}$ at a power density of $798 \mathrm{~W} \mathrm{~kg}^{-1}$ with outstanding electrochemical stability. Meanwhile, quasi-solid-state devices were prepared to demonstrate their practical application in flexible devices.

\section{EXPERIMENTAL SECTION}

\section{Synthesis of $\mathrm{CoNi}_{2} \mathrm{~S}_{4} / \mathrm{rGO}$}

In a typical synthesis for $\mathrm{CoNi}_{2} \mathrm{~S}_{4} / \mathrm{rGO}, \mathrm{GO}$ was dispersed in deionized water with the assistance of sonication for $30 \mathrm{~min}$ to form $\mathrm{GO}$ suspension $\left(1 \mathrm{mg} \mathrm{m}^{-1}\right)$. Then, $0.33 \mathrm{mmol}$ of $\mathrm{CoCl}_{2} \cdot 6 \mathrm{H}_{2} \mathrm{O}$ and $0.66 \mathrm{mmol}$ of $\mathrm{NiCl}_{2} \cdot 6 \mathrm{H}_{2} \mathrm{O}$ were added to the $\mathrm{GO}$ suspension and stirred for $10 \mathrm{~min}$. Then, $32 \mathrm{~mL}$ of potassium ethylxanthate solution $\left(0.1 \mathrm{~g} \mathrm{~mL}^{-1}\right)$ was added into the above solution dropwise with vigorously stirring for $8 \mathrm{~h}$ to form $\mathrm{CoNi}_{2} \mathrm{~S}_{4}$-Precursor/GO. After drying, the sample was annealed in a furnace with a ramping rate of $2^{\circ} \mathrm{C} \mathrm{min}{ }^{-1}$ to $500^{\circ} \mathrm{C}$ and kept for $2 \mathrm{~h}$ under $\mathrm{N}_{2}$ atmosphere. The final products were washed with deionized water and ethanol for six times. A series of the $\mathrm{CoNi}_{2} \mathrm{~S}_{4} / \mathrm{rGO}$ hybrids were fabricated based on the same procedure with different amounts of $\mathrm{GO}(8,16,24 \mathrm{mg})$, yielding samples labeled as $\mathrm{CoNi}_{2} \mathrm{~S}_{4} / \mathrm{rGO}-1, \mathrm{CoNi}_{2} \mathrm{~S}_{4} / \mathrm{rGO}-2$, and $\mathrm{CoNi}_{2} \mathrm{~S}_{4} / \mathrm{rGO}-3$, respectively.

\section{Syntheses of $\mathrm{CoS}, \mathrm{Ni}_{x} \mathrm{Co}_{3-x} \mathrm{~S}_{4}$, and NiS at different temperatures}

Typically, $1 \mathrm{mmol}$ of metal salt was prepared with different feed ratios of $\mathrm{CoCl}_{2} \cdot 6 \mathrm{H}_{2} \mathrm{O}$ and $\mathrm{NiCl}_{2} \cdot 6 \mathrm{H}_{2} \mathrm{O}$ from 1:0, 2:1, 1:1, 1:2, and 0:1 under stirring for $30 \mathrm{~min}$. Then, $32 \mathrm{~mL}$ of potassium ethylxanthate solution $\left(0.1 \mathrm{~g} \mathrm{~mL}^{-1}\right)$ was dropwise added into the above solution. The products were filtrated and washed several times with deionized water and dried under vacuum for $6 \mathrm{~h}$. The dried sample was annealed in a furnace with a ramping rate of $2^{\circ} \mathrm{C} \mathrm{min}^{-1}$ to $400 / 500 / 600^{\circ} \mathrm{C}$ and kept for $2 \mathrm{~h}$ under $\mathrm{N}_{2}$ atmosphere. The final products were washed with deionized water and ethanol for six times, and the corresponding samples were named as $\mathrm{CoS}-400, \mathrm{NiCo}_{2} \mathrm{~S}_{4}-400$, $\mathrm{Ni}_{1.5} \mathrm{Co}_{1.5} \mathrm{~S}_{4}-400, \quad \mathrm{CoNi}_{2} \mathrm{~S}_{4}-400, \quad \mathrm{NiS}-400, \quad \mathrm{CoS}-500$, $\mathrm{NiCo}_{2} \mathrm{~S}_{4}-500, \quad \mathrm{Ni}_{1.5} \mathrm{Co}_{1.5} \mathrm{~S}_{4}-500, \quad \mathrm{CoNi}_{2} \mathrm{~S}_{4}-500, \mathrm{NiS}-500$, $\mathrm{CoS}-600, \mathrm{NiCo}_{2} \mathrm{~S}_{4}-600, \mathrm{Ni}_{1.5} \mathrm{Co}_{1.5} \mathrm{~S}_{4}-600, \mathrm{CoNi}_{2} \mathrm{~S}_{4}-600$, and NiS-600. 


\section{Synthesis of other metal sulfide/rGo}

Typically, $1 \mathrm{mmol}$ of metal salt was added into $15 \mathrm{~mL}$ of GO suspension $\left(1 \mathrm{mg} \mathrm{mL}^{-1}\right)$ and stirred for $10 \mathrm{~min}$, and then $32 \mathrm{~mL}$ of potassium ethylxanthate solution $\left(0.1 \mathrm{~g} \mathrm{~mL}^{-1}\right)$ was dropwise added into the above solution. The dried sample was annealed in a furnace with a ramping rate of $2^{\circ} \mathrm{C} \mathrm{min}{ }^{-1}$ to $300^{\circ} \mathrm{C}$ and kept for $2 \mathrm{~h}$ under $\mathrm{N}_{2}$ atmosphere. The final products are named as $\mathrm{CdS} / \mathrm{rGO}, \mathrm{Cu}_{1.8} \mathrm{~S} / \mathrm{rGO}, \mathrm{In}_{2} \mathrm{~S}_{3} / \mathrm{rGO}, \mathrm{FeS} / \mathrm{rGO}, \mathrm{MnS} / \mathrm{rGO}$, and $\mathrm{ZnS} / \mathrm{rGO}$, which were prepared by using the corresponding metal salts $\mathrm{CdCl}_{2} \cdot 1 / 2 \mathrm{H}_{2} \mathrm{O},\left(\mathrm{Cu}\left(\mathrm{NO}_{3}\right)_{2} \cdot 3 \mathrm{H}_{2} \mathrm{O}\right.$, $\mathrm{InCl}_{3} \cdot 4 \mathrm{H}_{2} \mathrm{O}, \mathrm{FeSO}_{4} \cdot 7 \mathrm{H}_{2} \mathrm{O}, \mathrm{MnCl}_{2}$, and $\mathrm{Zn}\left(\mathrm{CH}_{3} \mathrm{COO}\right)_{2}$. $2 \mathrm{H}_{2} \mathrm{O}$, respectively.

\section{Characterizations}

The phase and structure were examined by X-ray powder diffraction (XRD, PERSEE, XD-3 with $\mathrm{Cu}$ Ka radiation). Raman spectra were conducted on a Horiba Micro Raman HR Evolution System with an excitation wavelength of $514.5 \mathrm{~nm}$. X-ray photoelectron spectroscopy (XPS, Thermo-VG; ESCALAB25OXi with Al Ka radiation) was used to investigate the elemental species and their chemical states. The morphologies of samples were investigated by field-emission scanning electron microscopy (FESEM, FEI, QuanTA-200F) and transmission electron microscopy (TEM, JEOL, JEM-2100F). The crystal structure information on nanoscale was examined by a high resolution TEM (HRTEM, JEOL, JEM-2100F). The porosity measurements and Brunauer-Emmett-Teller (BET) surface area of the as-synthesized electrode materials were examined by $\mathrm{N}_{2}$ sorption isotherms (Quantachrome, Autosorb-iQ at the testing temperature of $77 \mathrm{~K}$ ).

\section{Electrochemical measurements}

The electrochemical performances were evaluated by cyclic voltammetry $(\mathrm{CV})$, galvanostatic charge-discharge (GCD), and electrochemical impedance spectroscopy (EIS) measurements using a CHI660D electrochemical workstation (Chenhua, Shanghai) in a three-electrode system, and a two-electrode system for ASC devices. For preparing the working electrodes, the electroactive materials, acetylene black conductor and poly(vinylidenefluoride) (PVDF) were mixed in $N$-methyl pyrrolidone (NMP) with a weight ratio of 80:10:10. The mixture was first coated onto the Ni foam surface $\left(1 \times 1 \mathrm{~cm}^{2}\right)$, and the working electrode was obtained by drying at $60^{\circ} \mathrm{C}$ for $12 \mathrm{~h}$. The mass loading of the active material was $\sim 2 \mathrm{mg} \mathrm{cm}^{-2}$. A platinum plate, an $\mathrm{Ag} / \mathrm{AgCl}$ electrode, and $6 \mathrm{~mol} \mathrm{~L}^{-1} \mathrm{KOH}$ solution were used as the counter electrode, reference electrode and electrolyte, respectively, in a three-electrode system. The ASC devices were fabricated with $\mathrm{CoNi}_{2} \mathrm{~S}_{4} / \mathrm{rGO}-2$ hybrids $\left(\sim 0.6 \mathrm{mg} \mathrm{cm}^{-2}\right)$ as the cathode and AC $\left(\sim 2.3 \mathrm{mg} \mathrm{cm}^{-2}\right)$ as the anode, and $6 \mathrm{~mol} \mathrm{~L}^{-1} \mathrm{KOH}$ solution was used as the electrolyte. Sodium carboxymethyl cellulose (CMC)-KOH gel was used as electrolyte for quasi-solid-state devices. The CMC$\mathrm{KOH}$ gel electrolyte was prepared by adding $6 \mathrm{~g}$ of CMC and $10 \mathrm{~g}$ of $\mathrm{KOH}$ into $100 \mathrm{~mL}$ of deionized water under stirring at $90^{\circ} \mathrm{C}$ for $3 \mathrm{~h}$ until the gel became transparent.

\section{Calculations}

The specific capacitance of the single electrode $\left(C_{\mathrm{s}}\right)$ was examined by the GCD curves according to Equation (1):

$C_{\mathrm{s}}=\frac{1}{m \mathrm{~d} V / \mathrm{d} t}$,

where $I, m$, and $\mathrm{d} V / \mathrm{d} t$ are the current during the discharge process, the mass of the active electrodes, and the slope of the discharge curve, respectively.

The mass loading of the positive electrode to the negative electrode follows the following Equation (2):

$\frac{m_{+}}{m_{-}}=\frac{C_{\mathrm{s}} \Delta V_{-}}{C_{\mathrm{s}+} \Delta V_{+}}$.

Specific capacitance $(C)$, energy density $(E)$, and power density $(P)$ of the ASC devices follow Equations (3-5), respectively:

$C=\frac{1}{m \mathrm{~d} V / \mathrm{d} t}$,

$E=\frac{C(\Delta V)^{2}}{2 \times 3.6}$,

$P=\frac{E \times 3600}{\Delta t}$

where $m, \Delta V$, and $\Delta t$ are the total mass of the active materials $(\mathrm{g})$, the potential voltage $(\mathrm{V})$, and the discharge time (s), respectively. The mass of the active materials was calculated by subtracting the mass of the substrate from the coated substrate. The units of specific capacitance, energy density and power density are $\mathrm{F} \mathrm{g}^{-1}, \mathrm{~W} \mathrm{~h} \mathrm{~kg}^{-1}$ and $\mathrm{W} \mathrm{kg}^{-1}$, respectively.

\section{RESULTS AND DISCUSSION}

The preparation of $\mathrm{CoNi}_{2} \mathrm{~S}_{4} / \mathrm{rGO}$ hybrids is illustrated in Fig. 1. At first, $\mathrm{Co}^{2+}$ and $\mathrm{Ni}^{2+}$ were anchored on $\mathrm{GO}$ by intensively interaction with the oxygen-containing functional groups of $-\mathrm{OH}$ and $-\mathrm{COOH}$. Then, potassium ethylxanthate reacted with metal ions to form chelates on the surface of GO to form $\mathrm{CoNi}_{2} \mathrm{~S}_{4}$-Precursor/GO. After annealing, the $\mathrm{CoNi}_{2} \mathrm{~S}_{4}$-Precursor/GO was transformed into $\mathrm{CoNi}_{2} \mathrm{~S}_{4} / \mathrm{rGO}$. The growth of the $\mathrm{CoNi}_{2} \mathrm{~S}_{4}$ nanoparticles could be regulated by changing the concentra- 


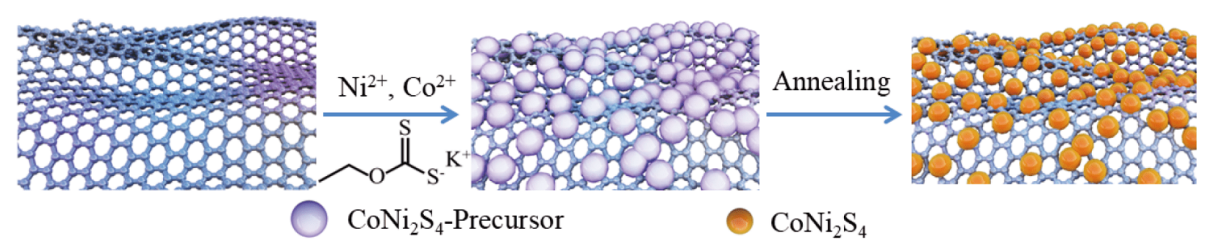

Figure 1 Schematic representation of the preparation of $\mathrm{CoNi}_{2} \mathrm{~S}_{4} / \mathrm{rGO}$.

tion of the GO suspenion. Three different $\mathrm{CoNi}_{2} \mathrm{~S}_{4} / \mathrm{rGO}$ hybrids referred to $\mathrm{CoNi}_{2} \mathrm{~S}_{4} / \mathrm{rGO}-1, \mathrm{CoNi}_{2} \mathrm{~S}_{4} / \mathrm{rGO}-2$, and $\mathrm{CoNi}_{2} \mathrm{~S}_{4} / \mathrm{rGO}-3$ have been investigated corresponding to the different quantities of GO. For comparison, the pristine $\mathrm{CoS}, \mathrm{NiCo}_{2} \mathrm{~S}_{4}, \mathrm{Ni}_{1.5} \mathrm{Co}_{1.5} \mathrm{~S}_{4}, \mathrm{CoNi}_{2} \mathrm{~S}_{4}, \mathrm{NiS}$ were synthesized by the same method but without the addition of GO at different temperatures. At the same time, this generalized method can be used to synthesize other metal sulfides, including $\mathrm{CdS}, \mathrm{Cu}_{1.8} \mathrm{~S}, \mathrm{In}_{2} \mathrm{~S}_{3}, \mathrm{FeS}, \mathrm{MnS}$, and $\mathrm{ZnS}$, which can be compounded with rGO to form composite materials with different morphologies.

The crystal structures of $\mathrm{CoNi}_{2} \mathrm{~S}_{4}$ and $\mathrm{CoNi}_{2} \mathrm{~S}_{4} / \mathrm{rGO}$ were investigated by XRD in Fig. 2a. The diffraction peaks located at $26.7^{\circ}, 31.5^{\circ}, 38.2^{\circ}, 50.3^{\circ}$, and $55.0^{\circ}$ are assigned to the (220), (311), (400), (511), and (440) planes of the cubic $\mathrm{CoNi}_{2} \mathrm{~S}_{4}$ (JCPDF No. 24-0334) [31]. The diffraction peaks for $\mathrm{rGO}$ in the $\mathrm{CoNi}_{2} \mathrm{~S}_{4} / \mathrm{rGO}$ were covered by the stronger diffraction peaks of $\mathrm{CoNi}_{2} \mathrm{~S}_{4}$. Furthermore, there are no other peaks attributed to impurities, confirming the high purity. Crystalline structures of the pristine $\mathrm{CoS}, \mathrm{Ni}_{x} \mathrm{Co}_{3-x} \mathrm{~S}_{4}$, and $\mathrm{NiS}$ formed at different temperatures $\left(400 / 500 / 600^{\circ} \mathrm{C}\right)$ are detailed in Fig. S1. Obviously, the crystal phase and crystallinity are affected by the annealing temperature and the ratio of $\mathrm{Ni}$
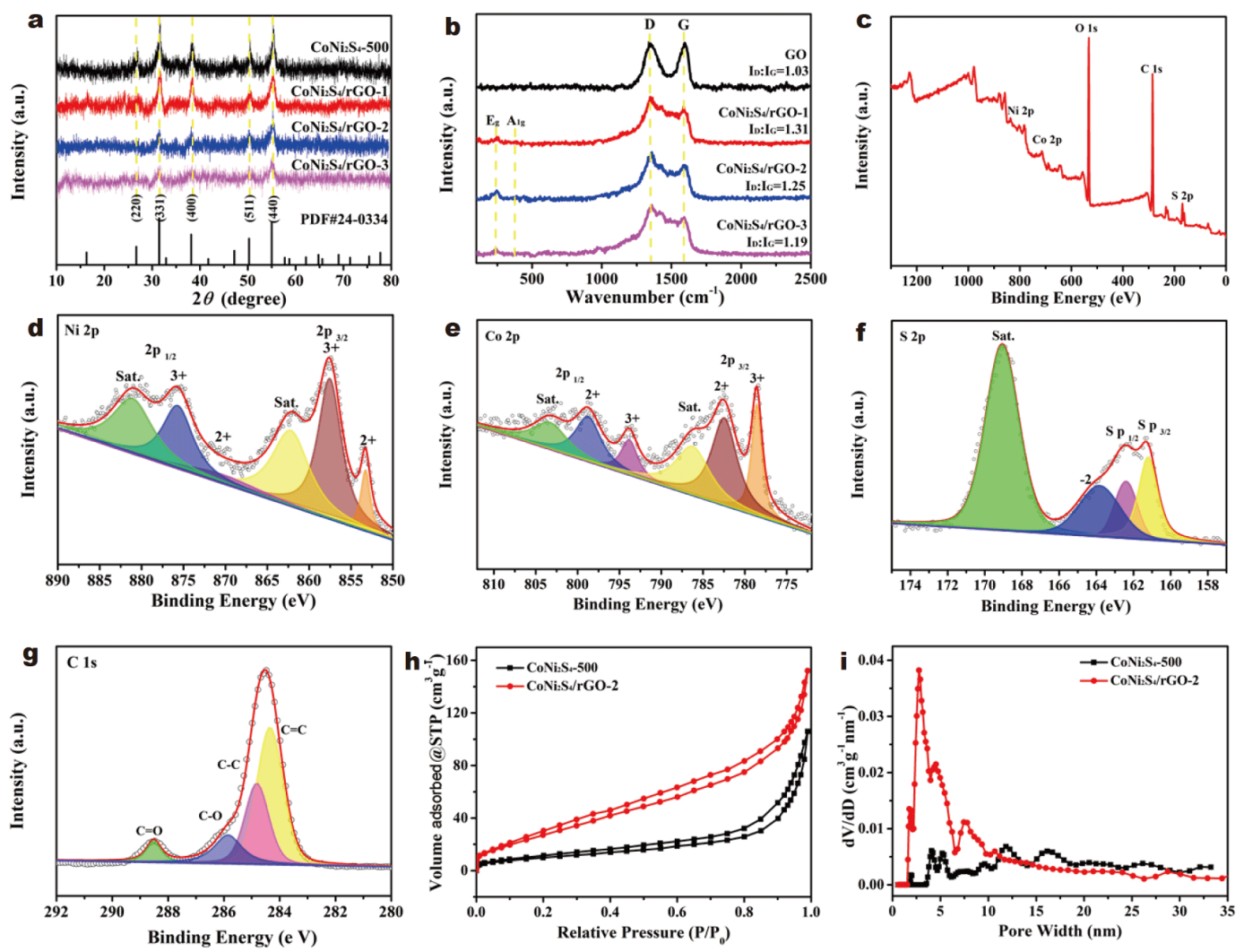

Figure 2 (a) XRD patterns of the $\mathrm{CoNi}_{2} \mathrm{~S}_{4}-500$ and $\mathrm{CoNi}_{2} \mathrm{~S}_{4} / \mathrm{rGO}$ hybrids. (b) Raman spectra of $\mathrm{GO}$ and $\mathrm{CoNi}_{2} \mathrm{~S}_{4} / \mathrm{rGO}$ hybrids. (c) XPS survey scan spectrum of $\mathrm{CoNi}_{2} \mathrm{~S}_{4} / \mathrm{rGO}-2$. (d-g) High resolution XPS spectra of Ni 2p, Co 2p, S 2p, and C 1s. (h) $\mathrm{N}_{2}$ adsorption/desorption isotherms and (i) the corresponding pore size distribution profiles of $\mathrm{CoNi}_{2} \mathrm{~S}_{4}-500$ and $\mathrm{CoNi}_{2} \mathrm{~S}_{4} / \mathrm{rGO}-2$. 
to Co. Hence, the reaction process principally requires optimal $\mathrm{Ni}$ to Co ratio and annealing temperature. Besides, the XRD patterns of other metal sulfide/rGO obtained by this generalized method are detailed in Fig. S2. These results prove that this generalized method has been successfully used to prepare a variety of metal sulfide/ rGO hybrids, including $\mathrm{CdS} / \mathrm{rGO}, \mathrm{Cu}_{1.8} \mathrm{~S} / \mathrm{rGO}, \mathrm{In}_{2} \mathrm{~S}_{3} /$ rGO, FeS/rGO, MnS/rGO, and $\mathrm{ZnS} / \mathrm{rGO}$. The local structures of $\mathrm{GO}$ and $\mathrm{CoNi}_{2} \mathrm{~S}_{4} / \mathrm{rGO}$ were further investigated by Raman spectrum (Fig. 2b).Two characteristic peaks of the $\mathrm{D}$ and $\mathrm{G}$ bands of the $\mathrm{CoNi}_{2} \mathrm{~S}_{4} / \mathrm{rGO}-2$ hybrids are centered at about 1350 and $1585 \mathrm{~cm}^{-1}$, respectively. The two peaks at 240 and $375 \mathrm{~cm}^{-1}$ in the Raman spectrum are assigned to the $\mathrm{E}_{\mathrm{g}}$ and $\mathrm{A}_{\mathrm{lg}}$ modes of $\mathrm{CoNi}_{2} \mathrm{~S}_{4}$ nanoparticles, respectively. In contrast to the $\mathrm{GO}$, the $I_{\mathrm{D}} / I_{\mathrm{G}}$ ratios of the $\mathrm{CoNi}_{2} \mathrm{~S}_{4} / \mathrm{rGO}$ hybrids increase slightly from 1.03 to $1.31,1.25$ and 1.19 , respectively, proving that more structural defects exist in $\mathrm{CoNi}_{2} \mathrm{~S}_{4} / \mathrm{rGO}$ hybrids than pure GO. The increase of $I_{\mathrm{D}} / I_{\mathrm{G}}$ ratio is obviously associated with the compact anchoring of $\mathrm{CoNi}_{2} \mathrm{~S}_{4}$ nanoparticles on the rGO surface [38].

The surface information of the $\mathrm{CoNi}_{2} \mathrm{~S}_{4} / \mathrm{rGO}-2$ hybrids was investigated by XPS. The presence of $\mathrm{Ni}, \mathrm{Co}, \mathrm{S}$, and $\mathrm{C}$ in $\mathrm{CoNi}_{2} \mathrm{~S}_{4} / \mathrm{rGO}-2$ hybrids is supported by the XPS survey spectrum, as shown in Fig. 2c. The $\mathrm{Ni}, \mathrm{Co}, \mathrm{S}$, and $\mathrm{C}$ contents are estimated to be $4.00,2.77,28.26$, and 64.96 at $\%$, respectively. The Ni $2 p$ spectrum could be deconvoluted into two shakeup satellites and two spinorbit doublets (Fig. 2d). The binding energies at 853.3 and $870.7 \mathrm{eV}$ are ascribed to $\mathrm{Ni}^{2+}$, and the peaks located at 856.4 and $875.7 \mathrm{eV}$ are ascribed to $\mathrm{Ni}^{3+}$. The peaks at 882.9 and $863.5 \mathrm{eV}$ are assigned to the satellite peaks [44]. For the Co $2 p$ spectrum (Fig. 2e), the binding energy located at 783.9 and $798.2 \mathrm{eV}$ are attributed to $\mathrm{Co}^{2+}$ ions, and the peaks at 778.8 and $793.9 \mathrm{eV}$ belong to $\mathrm{Co}^{3+}$. Besides, two peaks at 787.7 and $803.6 \mathrm{eV}$ corresponding to satellite peaks are observed [45]. The S $2 p$ spectrum exhibits two main binding energies located at 161.7 and $162.8 \mathrm{eV}$ (Fig. 2f) ascribed to the $\mathrm{S} 2 \mathrm{p}_{3 / 2}$ and $\mathrm{S} 2 \mathrm{p}_{1 / 2}$, respectively [34]. The deconvoluted C 1s spectrum (Fig. 2g) include four peaks, corresponding to $\mathrm{C}=\mathrm{C}(284.5 \mathrm{eV}), \mathrm{C}-$ $\mathrm{C}(285.1 \mathrm{eV}), \mathrm{C}-\mathrm{O}(286.0 \mathrm{eV})$, and $\mathrm{C}=\mathrm{O}(288.5 \mathrm{eV})$, respectively [46]. The relatively high intense and narrow peak of $\mathrm{C}=\mathrm{C}$ bond demonstrates that most of the carbons in rGO have been restored to $\mathrm{sp}^{2}$ hybridized carbons [47]. The XPS spectra of the $\mathrm{CoS}, \mathrm{Ni}_{x} \mathrm{Co}_{3-x} \mathrm{~S}_{4}$, and $\mathrm{NiS}$ are detailed in Figs S3-S7, which can demonstrate elemental components and chemical states of the corresponding compounds.

Note that enlarging the surface area of active materials with porous structure can provide a myriad of active sites and superior electrochemical performance [48]. Fig. $2 \mathrm{~h}$ displays the $\mathrm{N}_{2}$ adsorption and desorption isotherms of $\mathrm{CoNi}_{2} \mathrm{~S}_{4}$ and $\mathrm{CoNi}_{2} \mathrm{~S}_{4} / \mathrm{rGO}-2$ hybrids. The $\mathrm{CoNi}_{2} \mathrm{~S}_{4} / \mathrm{rGO}-$ 2 hybrids show the type IV isotherm. The existence of a large number of mesopores is proved by high uptakes of $\mathrm{N}_{2}$ at $P / P_{0} \sim 1$ [49]. The pore-size distribution curves based on Barett-Joyner-Halenda (BJH) method in Fig. 2i present narrow pore-size distribution concentrated at $2.8 \mathrm{~nm}$, indicating that there is large amount of mesopores within this range. Moreover, compared with the pristine $\mathrm{CoNi}_{2} \mathrm{~S}_{4}$ sample with a surface area of $36.8 \mathrm{~m}^{2} \mathrm{~g}^{-1}$, the composite $\mathrm{CoNi}_{2} \mathrm{~S}_{4} / \mathrm{rGO}-2$ shows a higher specific surface area of $121.9 \mathrm{~m}^{2} \mathrm{~g}^{-1}$. The porous structure of $\mathrm{CoNi}_{2} \mathrm{~S}_{4} / \mathrm{rGO}-2$ with larger specific surface area has promotive effect on the rapid diffusion of electron/ions [50].

The morphologies of the obtained samples were examined by FESEM. The FESEM images of pure GO and the $\mathrm{CoNi}_{2} \mathrm{~S}_{4}$-Precursor/GO are displayed in Fig. S8. Obviously, the $\mathrm{CoNi}_{2} \mathrm{~S}_{4}$-Precursor/GO has a rougher surface than GO, indicating that the precursor was successfully loaded onto the GO surface. As shown in Fig. 3a, b, the FESEM images show that the pristine $\mathrm{CoNi}_{2} \mathrm{~S}_{4}$ tends to form bulky aggregations without rGO. These aggregated $\mathrm{CoNi}_{2} \mathrm{~S}_{4}$ will trigger reduced contact area with the electrolyte to retard the redox reaction kinetics of the electroactive materials. The FESEM images of $\mathrm{CoNi}_{2} \mathrm{~S}_{4} / \mathrm{rGO}-1$ (Fig. 3c, d) composite with the least rGO content show that spherical structure was fixed on the surface of rGO, and vigorous agglomeration occurs due to the insufficient rGO. Fig. 3e, f displays the FESEM images of the $\mathrm{CoNi}_{2} \mathrm{~S}_{4} /$ rGO-2. Evidently, the $\mathrm{CoNi}_{2} \mathrm{~S}_{4}$ nanoparticles are ultradispersed on $\mathrm{rGO}$ owing to the content of $\mathrm{rGO}$ reaching the appropriate level. Moreover, the FESEM images of the $\mathrm{CoNi}_{2} \mathrm{~S}_{4} / \mathrm{rGO}-3$ (Fig. 3g, h) with excessive rGO show that small amount of $\mathrm{CoNi}_{2} \mathrm{~S}_{4}$ particles are distributed unevenly on the surface of rGO. Besides, more exquisite differences of $\mathrm{CoNi}_{2} \mathrm{~S}_{4}$ nanoparticles dispersion are shown by the model structure of pristine $\mathrm{CoNi}_{2} \mathrm{~S}_{4}$, $\mathrm{CoNi}_{2} \mathrm{~S}_{4} / \mathrm{rGO}-1, \mathrm{CoNi}_{2} \mathrm{~S}_{4} / \mathrm{rGO}-2$, and $\mathrm{CoNi}_{2} \mathrm{~S}_{4} / \mathrm{rGO}-3$ in Fig. 3b-1, d-1, f-1 and h-1, respectively.

The morphologies and structures of $\mathrm{CoNi}_{2} \mathrm{~S}_{4} / \mathrm{rGO}$ were further examined by TEM and HRTEM. The TEM image of $\mathrm{CoNi}_{2} \mathrm{~S}_{4} / \mathrm{rGO}-1$ depicted in Fig. 4 a reveals that the $\mathrm{CoNi}_{2} \mathrm{~S}_{4}$ nanoparticles are aggregated on the rGO nanosheets. In sharp contrast, the TEM image of $\mathrm{CoNi}_{2} \mathrm{~S}_{4} /$ rGO-2 (Fig. 4b) shows that small-sized $\mathrm{CoNi}_{2} \mathrm{~S}_{4}$ nanoparticles are uniformly distributed on the rGO nanosheets. The TEM image of $\mathrm{CoNi}_{2} \mathrm{~S}_{4} / \mathrm{rGO}-3$ (Fig. 4c) 

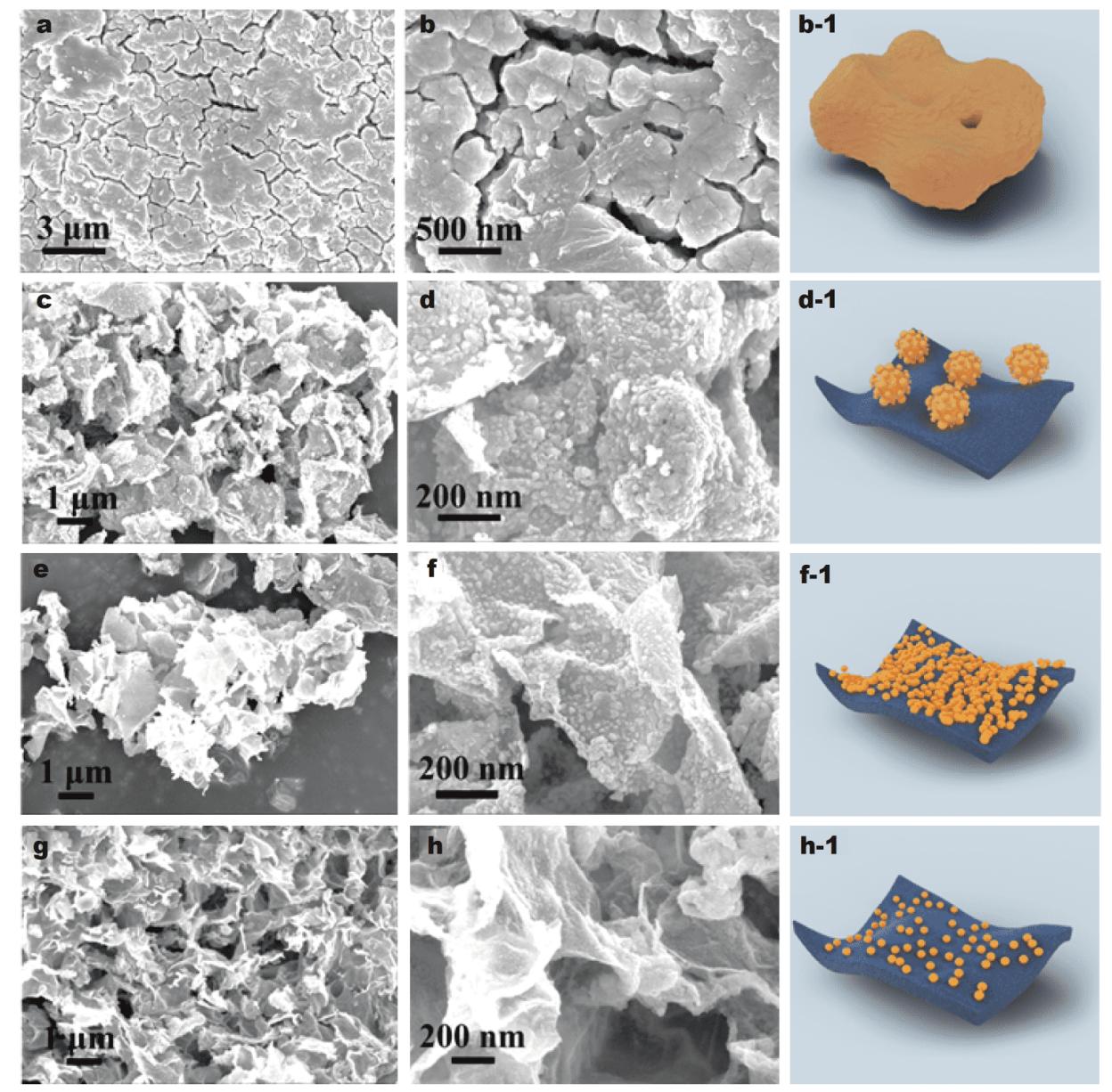

Figure 3 (a, b) FESEM images and (b-1) model structure of $\mathrm{CoNi}_{2} \mathrm{~S}_{4}-500$. (c, d) FESEM images and (d-1) model structure of CoNi $\mathrm{S}_{4} / \mathrm{rGO}-1$. (e, f) FESEM images and (f-1) model structure of $\mathrm{CoNi}_{2} \mathrm{~S}_{4} / \mathrm{rGO}-2$. (g, h) FESEM images and (h-1) model structure of CoNi $\mathrm{S}_{4} / \mathrm{rGO}_{4}$.

shows that slight and uneven $\mathrm{CoNi}_{2} \mathrm{~S}_{4}$ nanoparticles are fixed on the rGO nanosheets. The TEM images in Fig. $4-\mathrm{c}$ are in agreement with the corresponding FESEM results. Besides, the structure of the nanoparticles-onnanosheets can be favorably maintained in a large scale (Fig. S9). As a result, the FESEM and TEM images show that the optimal product possesses ultradispersed $\mathrm{CoNi}_{2} \mathrm{~S}_{4}$ nanoparticles on $\mathrm{rGO}$ with appropriate amount of GO. At the same time, these images reveal that the $\mathrm{CoNi}_{2} \mathrm{~S}_{4} / \mathrm{rGO}$ 2 feature the rich active sites, which is propitious to improve the specific capacitance. As depicted in Fig. 4 d, the statistical size distribution of $\mathrm{CoNi}_{2} \mathrm{~S}_{4} / \mathrm{rGO}-2$ displays the mean size of $\mathrm{CoNi}_{2} \mathrm{~S}_{4}$ nanoparticles is $16.7 \mathrm{~nm}$. The HRTEM image of $\mathrm{CoNi}_{2} \mathrm{~S}_{4} / \mathrm{rGO}-2$ (Fig. 4e) confirms the rGO nanosheets flawlessly encapsulate the $\mathrm{CoNi}_{2} \mathrm{~S}_{4}$ nanoparticles, implying the strong association of $\mathrm{CoNi}_{2} \mathrm{~S}_{4}$ and rGO. The interplanar spacings of about 0.184 and $0.166 \mathrm{~nm}$ correspond to (511) and (440) planes of
$\mathrm{CoNi}_{2} \mathrm{~S}_{4}$, respectively. At the same time, the corresponding selected area electron diffraction (SAED) image depicted in Fig. $4 \mathrm{f}$ reveals the polycrystalline nature of $\mathrm{CoNi}_{2} \mathrm{~S}_{4} / \mathrm{rGO}-2$. The diffraction rings can be well indexed to (111), (220), (311), (400), (551), and (440) crystal planes of $\mathrm{CoNi}_{2} \mathrm{~S}_{4}$. Besides, the obvious hexagonal ring can be assigned to the structure of rGO. The $\mathrm{CoNi}_{2} \mathrm{~S}_{4} /$ rGO-2 was further analyzed by high-angle annular darkfield scanning TEM (HAADF-STEM) with energy dispersive spectrometer (EDS) analysis (Fig. 4g). The EDS mapping shows the coexistence of $\mathrm{C}, \mathrm{Co}, \mathrm{Ni}$, and $\mathrm{S}$ elements which are homogeneously distributed throughout the $\mathrm{CoNi}_{2} \mathrm{~S}_{4} / \mathrm{rGO}-2$ nanosheets, further confirming the uniformly dispersion of $\mathrm{CoNi}_{2} \mathrm{~S}_{4}$ nanoparticles on rGO nanosheets. The EDS line scanning (Fig. S10) was further used to reveal the element distribution, which also demonstrated the well-proportioned dispersion of $\mathrm{C}$, Co, $\mathrm{Ni}$, and $\mathrm{S}$. 

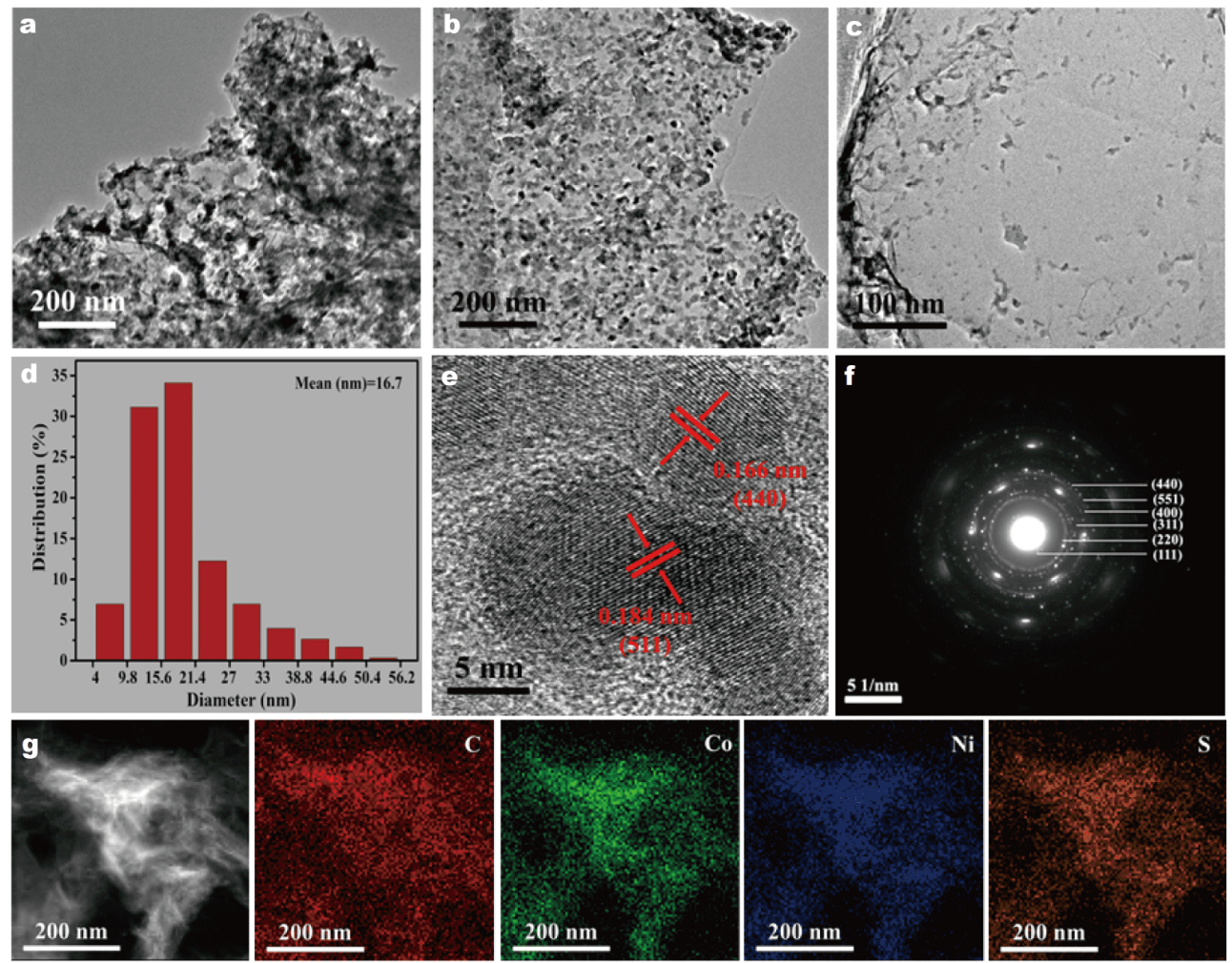

Figure 4 TEM images of (a) $\mathrm{CoNi}_{2} \mathrm{~S}_{4} / \mathrm{rGO}-1$, (b) $\mathrm{CoNi}_{2} \mathrm{~S}_{4} / \mathrm{rGO}-2$, and (c) $\mathrm{CoNi}_{2} \mathrm{~S}_{4} / \mathrm{rGO}-3$. (d) The statistical size distribution of CoNi $\mathrm{S}_{4} / \mathrm{rGO}-2$ obtained from TEM photographs. (e) HRTEM image of $\mathrm{CoNi}_{2} \mathrm{~S}_{4} / \mathrm{rGO}-2$ hybrids. (f) SAED pattern for $\mathrm{CoNi}_{2} \mathrm{~S}_{4} / \mathrm{rGO}-2$. (g) HAADF-STEM image and the corresponding elemental mapping images of $\mathrm{CoNi}_{2} \mathrm{~S}_{4} / \mathrm{rGO}-2$.

The morphological characteristics of other metal sulfide/rGO hybrids prepared by this method are detailed in Figs S11-S16. Apparently, the $\mathrm{CdS} / \mathrm{rGO}, \mathrm{Cu}_{1.8} \mathrm{~S} / \mathrm{rGO}$, $\mathrm{MnS} / \mathrm{rGO}$, and $\mathrm{ZnS} / \mathrm{rGO}$ also show the morphology of nanoparticles anchored on the surface of rGO. In addition, the morphological images of $\operatorname{In}_{2} \mathrm{~S}_{3} / \mathrm{rGO}$ and FeS/ rGO show unique nanoflower and nanocluster structures, respectively. The corresponding SAED images reveal the crystalline natures of the metal sulfides. It shows that complex morphologies can also be prepared by this simple method under mild conditions.

The electrochemical performances of $\mathrm{CoS}, \mathrm{Ni}_{x} \mathrm{Co}_{3-x} \mathrm{~S}_{4}$, and NiS were firstly analyzed in a standard three electrode systems by CV, GCD and EIS, as shown in Figs S17-S21. These results clearly demonstrate that both temperature and ratio of nickel to cobalt play very important function on specific capacitance and electron/ion diffusion. The specific capacitance data under different conditions are summarized in Fig. 5a. Obviously, the optimal products are obtained at the annealing temperature of $500^{\circ} \mathrm{C}$ and the ratio of nickel to cobalt of $2: 1$, which delivers the highest capacitance of $1304 \mathrm{Fg}^{-1}$ at
$2 \mathrm{Ag}^{-1}$.

The electrochemical performances of $\mathrm{CoNi}_{2} \mathrm{~S}_{4} / \mathrm{rGO}$ were further systematically investigated. The integrated $\mathrm{CV}$ area of $\mathrm{CoNi}_{2} \mathrm{~S}_{4} / \mathrm{rGO}-2$ is obviously larger than $\mathrm{CoNi}_{2} \mathrm{~S}_{4} / \mathrm{rGO}-1, \mathrm{CoNi}_{2} \mathrm{~S}_{4} / \mathrm{rGO}-3$, and $\mathrm{CoNi}_{2} \mathrm{~S}_{4}-500$, which proves that $\mathrm{CoNi}_{2} \mathrm{~S}_{4} / \mathrm{rGO}-2$ shows a larger specific capacitance (Fig. 5b). As displayed in Fig. 5c, the representative $\mathrm{CV}$ curves of $\mathrm{CoNi}_{2} \mathrm{~S}_{4} / \mathrm{rGO}-2$ at scan rates ranging from 5 to $100 \mathrm{mV} \mathrm{s}^{-1}$ in $-0.1-0.5 \mathrm{~V}$ show obvious redox peaks, resulting from the Faradaic reactions of $\mathrm{Ni}^{2+} / \mathrm{Ni}^{3+}$ and $\mathrm{Co}^{2+} / \mathrm{Co}^{3+}$ transitions associated with $\mathrm{OH}^{-}$ during the electrochemical process. The similar CV curve shapes were observed even at high scan rate, indicating that $\mathrm{CoNi}_{2} \mathrm{~S}_{4} / \mathrm{rGO}-2$ hybrids delivered excellent pseudocapacitance behavior and rate capability. The Faradaic redox processes follow the reaction below [24]:

$\mathrm{CoNi}_{2} \mathrm{~S}_{4}+2 \mathrm{OH}^{-} \leftrightarrow \mathrm{CoS}_{2 x} \mathrm{OH}+\mathrm{Ni}_{2} \mathrm{~S}_{4-2 x} \mathrm{OH}+2 \mathrm{e}^{-}$.

The GCD measurements of $\mathrm{CoNi}_{2} \mathrm{~S}_{4} / \mathrm{rGO}-2$ were implemented in $-0.1-0.4 \mathrm{~V}$ at different current densities (Fig. 5d). Based on the GCD profiles, the specific capacitances of $\mathrm{CoNi}_{2} \mathrm{~S}_{4} / \mathrm{rGO}-2$ are $1526,1430,1382,1208$, 

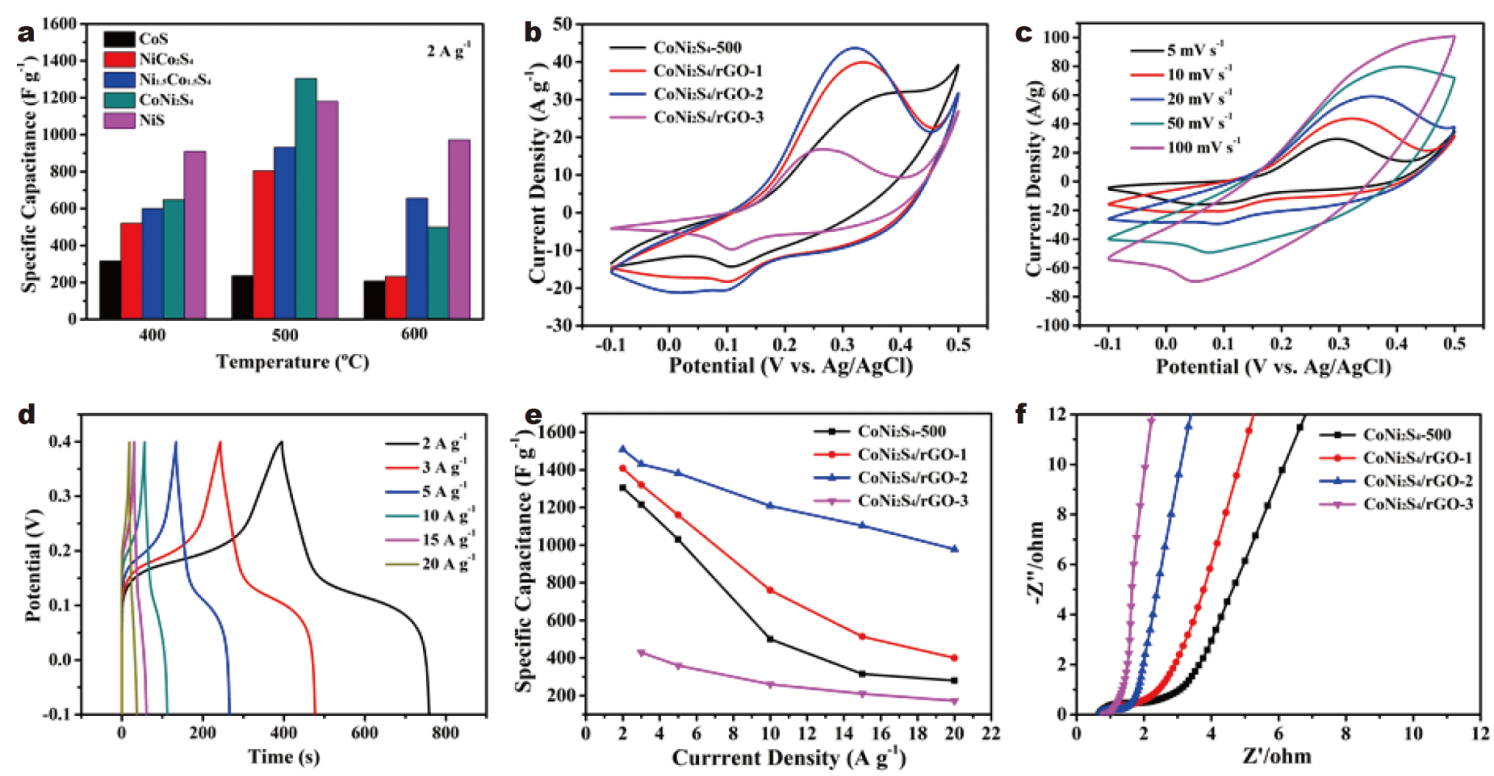

Figure 5 (a) Specific capacitances of $\mathrm{CoS}, \mathrm{Ni}_{x} \mathrm{Co}_{3-x} \mathrm{~S}_{4}$, and NiS prepared at different temperatures. (b) CV curves of $\mathrm{CoNi}_{2} \mathrm{~S}_{4}-500$, and $\mathrm{CoNi}_{2} \mathrm{~S}_{4} / \mathrm{rGO}$ hybrids. (c) $\mathrm{CV}$ curves of $\mathrm{CoNi}_{2} \mathrm{~S}_{4} / \mathrm{rGO}-2$ electrode at various scan rates. (d) GCD curves of $\mathrm{CoNi}_{2} \mathrm{~S}_{4} / \mathrm{rGO}-2$ at various current densities. (e) Specific capacitances of $\mathrm{CoNi}_{2} \mathrm{~S}_{4}-500$ and $\mathrm{CoNi}_{2} \mathrm{~S}_{4} / \mathrm{rGO}$ hybrids at different current densities. (f) EIS curves of $\mathrm{CoNi}_{2} \mathrm{~S}_{4}-500$ and CoNi $\mathrm{S}_{4} / \mathrm{rGO}$ hybrids.

1103 , and $988 \mathrm{Fg}^{-1}$ at $2,3,5,10,15$, and $20 \mathrm{Ag}^{-1}$, respectively. This suggests that small $\mathrm{CoNi}_{2} \mathrm{~S}_{4}$ nanoparticles homogeneously dispersed on rGO provide more active sites which play a decisive role in enhancing the specific capacitance. Integrating the GCD curves, the corresponding specific capacitances of $\mathrm{CoNi}_{2} \mathrm{~S}_{4}-500$ and $\mathrm{CoNi}_{2} \mathrm{~S}_{4} / \mathrm{rGO}$ electrodes are displayed in Fig. 5e. Apparently, when the current density rises from 2 to $20 \mathrm{Ag}^{-1}$, the specific capacitance of the $\mathrm{CoNi}_{2} \mathrm{~S}_{4} / \mathrm{rGO}-2$ electrode drops by $35 \%$, indicating good rate capability. Moreover, the $\mathrm{CoNi}_{2} \mathrm{~S}_{4} / \mathrm{rGO}-2$ electrode delivers high capacitance retention and coulombic efficiency, which can be attributed to the highly reversible Faradaic reaction (Fig. S22).

The superior electrochemical performance of $\mathrm{CoNi}_{2} \mathrm{~S}_{4} /$ rGO-2 hybrids could be attributed to the following factors: i) rGO could provide a myriad of nucleation sites for $\mathrm{CoNi}_{2} \mathrm{~S}_{4}$, greatly inhibiting the aggregation of $\mathrm{CoNi}_{2} \mathrm{~S}_{4}$ and forming small-sized $\mathrm{CoNi}_{2} \mathrm{~S}_{4}$ nanoparticles. Numerous small $\mathrm{CoNi}_{2} \mathrm{~S}_{4}$ nanoparticles on rGO nanosheets could vitally shorten the diffusion distance of active electron/ion. ii) The rGO nanosheets could effectively withstand the serious volume expansion of $\mathrm{CoNi}_{2} \mathrm{~S}_{4}$ nanoparticles during rapid charge/discharge process. Hence, the rate capability of $\mathrm{CoNi}_{2} \mathrm{~S}_{4} / \mathrm{rGO}-2$ can be obviously improved. iii) $\mathrm{CoNi}_{2} \mathrm{~S}_{4}$ nanoparticles deposited on the rGO nanosheets greatly inhibited the accumulation of rGO nanosheets, resulting in high double-layer capacitance.
To better understand the influence of rGO, the electrochemical impedances of $\mathrm{CoNi}_{2} \mathrm{~S}_{4}$ and $\mathrm{CoNi}_{2} \mathrm{~S}_{4} / \mathrm{rGO}$ hybrids were tested by using EIS. As shown in Fig. $5 f$, the impedance spectra show a semicircle in the high frequencies and a sloped straight line in the low frequencies [51]. In the high frequency region, the $\mathrm{CoNi}_{2} \mathrm{~S}_{4} / \mathrm{rGO}-2$ electrode delivers the equivalent series resistance of $1.6 \Omega$, which is lower than $1.8 \Omega$ of $\mathrm{CoNi}_{2} \mathrm{~S}_{4} / \mathrm{rGO}-1$ and $2.3 \Omega$ of $\mathrm{CoNi}_{2} \mathrm{~S}_{4}-500$, and higher than $1.2 \Omega$ of $\mathrm{CoNi}_{2} \mathrm{~S}_{4} / \mathrm{rGO}-3$. In the low frequency region, the slope of $\mathrm{CoNi}_{2} \mathrm{~S}_{4} / \mathrm{rGO}-3$ shows the lowest diffusion resistance. In addition, the equivalent circuit diagram is shown in Fig. S23. The equivalent series resistances of $\mathrm{CoNi}_{2} \mathrm{~S}_{4}, \mathrm{CoNi}_{2} \mathrm{~S}_{4} / \mathrm{rGO}-1$, $\mathrm{CoNi}_{2} \mathrm{~S}_{4} / \mathrm{rGO}-2$, and $\mathrm{CoNi}_{2} \mathrm{~S}_{4} / \mathrm{rGO}-3$ are $0.69,0.68,0.71$, and $0.74 \Omega$, respectively, and the charge transfer resistances are $3.14,2.57,1.82$, and $1.16 \Omega$, respectively (Table S1). These phenomena are because the composites with more rGO have better conductivity. Moreover, the electrochemical properties of other metal sulfide/rGO hybrids are detailed in Figs S24-28, which prove that these metal sulfide/rGO hybrids are valuable in the field of SCs.

To further evaluate $\mathrm{CoNi}_{2} \mathrm{~S}_{4} / \mathrm{rGO}$ for practical application, ASCs were assembled with the $\mathrm{CoNi}_{2} \mathrm{~S}_{4} / \mathrm{rGO}-2$ hybrids and $\mathrm{AC}$ as the cathode and anode, respectively. The CV curves of the AC and $\mathrm{CoNi}_{2} \mathrm{~S}_{4} / \mathrm{rGO}-2$ electrodes with different mass loadings are displayed in Fig. 6a. The specific capacitance and potential window of $\mathrm{AC}$ are 

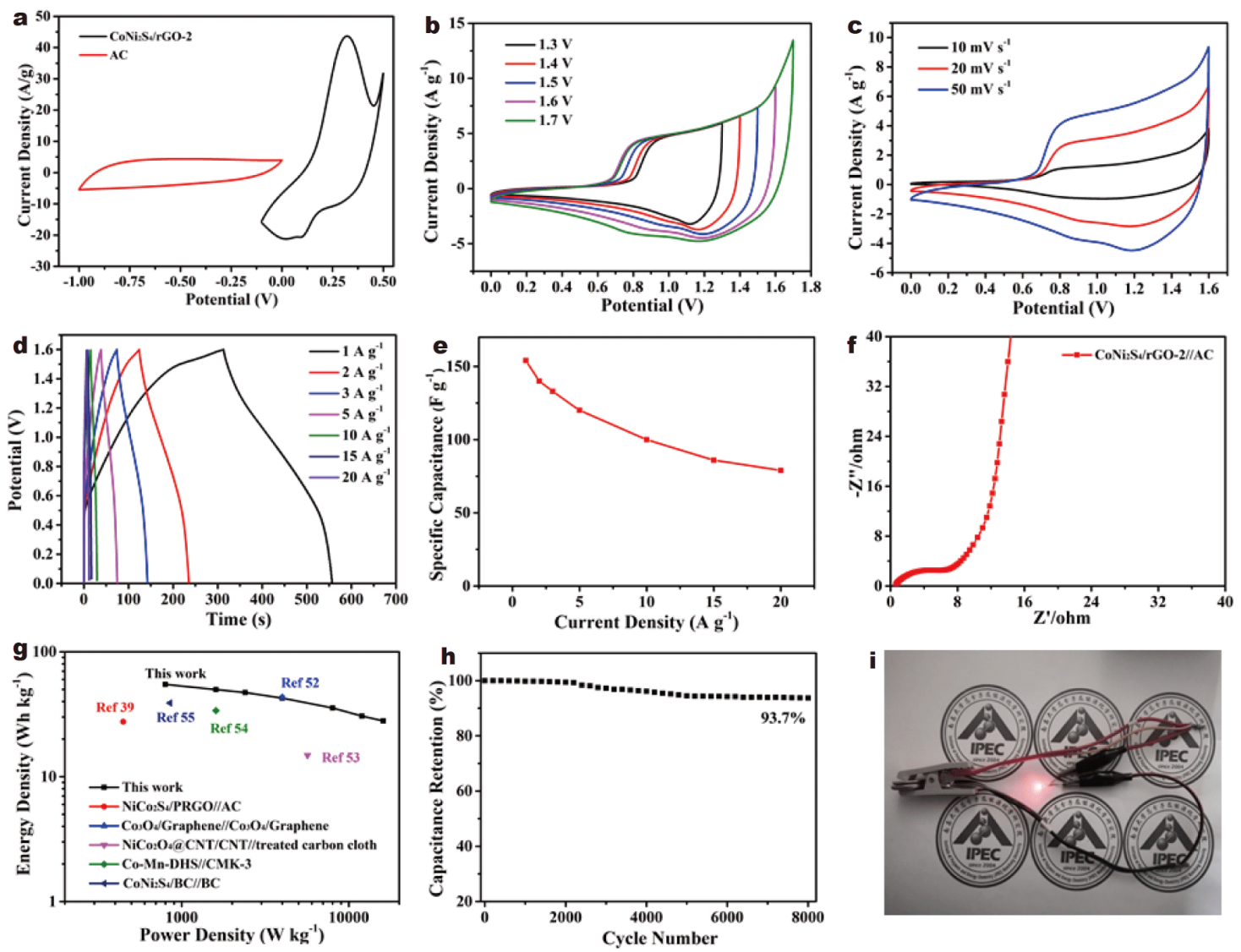

Figure 6 (a) $\mathrm{CV}$ curves of $\mathrm{AC}$ and $\mathrm{CoNi}_{2} \mathrm{~S}_{4} / \mathrm{rGO}-2$ at scan rate of $20 \mathrm{mV} \mathrm{s}^{-1}$. (b) $\mathrm{CV}$ curves of the ASC under various potential windows. (c) CV curves of the ASC at different scan rates. (d) GCD curves of the ASC at different current densities. (e) Specific capacitances of the ASC calculated from GCD curves. (f) EIS curves of the ASC. (g) Ragone plot of energy and power densities of the ASC compared with literature results. (h) Cycling performance at a constant current density of $3 \mathrm{Ag}^{-1}$. (i) Photographic image of a red LED operated by two ASC devices in series.

$185 \mathrm{~F} \mathrm{~g}^{-1}$ and $1 \mathrm{~V}$, respectively. To obtain an excellent performance of ASCs, the optimal mass ratio of the positive to negative electrodes $\left(\mathrm{m}^{+} / \mathrm{m}^{-}\right)$was adjusted to around 1:4. To evaluate the maximum potential window of the ASCs, CV curves under various potential windows at $50 \mathrm{mV} \mathrm{s}^{-1}$ were recorded (Fig. 6b). The CV curves demonstrate the ASCs show an outstanding capacitive behavior during $10-50 \mathrm{mV} \mathrm{s}^{-1}$ in the working voltage windows of $0-1.6 \mathrm{~V}$ (Fig. $6 \mathrm{c}$ ). The shape of $\mathrm{CV}$ curves changes slightly with the enhancement of current density, proving a superior rate capability of the ASCs. The GCD curves of the device at different current densities are shown in Fig. 6d. The device exhibits relatively low internal resistance drop, benefiting from the reduced electron/ion diffusion pathway. The specific capacitances of the supercapacitor device were calculated by the discharge curves. In Fig. 6e, the ASC device possesses specific capacitances of 154,140,133,120,100,86, and
$79 \mathrm{~F} \mathrm{~g}^{-1}$ at $1,2,3,5,10,15$, and $20 \mathrm{~A} \mathrm{~g}^{-1}$, respectively. The capacitance retention and coulombic efficiency of the ASC at different current densities are shown in Fig. S29. The coulombic efficiency at a current density of $1 \mathrm{~A} \mathrm{~g}^{-1}$ is only $82 \%$, which can be attributed to the incomplete discharge caused by some side reactions in the electrochemical redox reaction at low current density. The Nyquist plot (Fig. $6 \mathrm{f}$ ) shows the charge-transfer resistance value is $7.9 \Omega$ for the ASC devices. Fig. $6 \mathrm{~g}$ shows the Ragone plots of the energy and power density of the ASC device. The asymmetric supercapacitor delivers a high energy density of $54.8 \mathrm{~W} \mathrm{~h} \mathrm{~kg}^{-1}$ at a power density of $798 \mathrm{~W} \mathrm{~kg}^{-1}$. Notably, the energy density of ASC devices is more preferable than that of nickel/cobalt compositesbased devices, such as $\mathrm{NiCo}_{2} \mathrm{~S}_{4} / \mathrm{PRGO} / / \mathrm{AC}\left(27.5 \mathrm{~W} \mathrm{~h} \mathrm{~kg}{ }^{-1}\right.$ at $446.5 \mathrm{~W} \mathrm{~kg}^{-1}$ ) [39], $\mathrm{Co}_{3} \mathrm{O}_{4} / \mathrm{Graphene}_{/} / \mathrm{Co}_{3} \mathrm{O}_{4} / \mathrm{Graphene}$ (43.1 $\mathrm{W} \mathrm{h} \mathrm{kg}^{-1}$ at $4000 \mathrm{~W} \mathrm{~kg}^{-1}$ ) [52], $\mathrm{NiCo}_{2} \mathrm{O}_{4} @ \mathrm{CNT} /$ $\mathrm{CNT} / /$ treated carbon cloth $\left(27.6 \mathrm{~W} \mathrm{~h} \mathrm{~kg}^{-1}\right.$ at $\left.550 \mathrm{~W} \mathrm{~kg}^{-1}\right)$ 


\section{[53], Co-Mn-DHS//CMK-3 (33.8 $\mathrm{W} \mathrm{h} \mathrm{kg}^{-1} \quad$ at} $1602 \mathrm{~W} \mathrm{~kg}^{-1}$ ) [54], and $\mathrm{CoNi}_{2} \mathrm{~S}_{4} / \mathrm{BC} / / \mathrm{BC}\left(38.9 \mathrm{~W} \mathrm{~h} \mathrm{~kg}^{-1}\right.$ at $850 \mathrm{~W} \mathrm{~kg}^{-1}$ ) [55]. The cycling stability of the ASC was further investigated by the capacitance retention at current density of $3 \mathrm{Ag}^{-1}$ (Fig. 6h). Remarkably, the ASC maintains $93.7 \%$ of its original capacitance after 8000 cycles, demonstrating the outstanding long-term stability. To further prove the practical use of the $\mathrm{CoNi}_{2} \mathrm{~S}_{4} / \mathrm{rGO}-2 / /$ AC ASC device, a red light emitting diode (LED) can be lightened up by double ASC devices (Fig. 6i).

In view of developing flexible quasi-solid-state supercapacitors, we have fabricated supercapacitor devices using sodium carboxymethyl cellulose/KOH (CMC/ $\mathrm{KOH})$ electrolyte separating $\mathrm{CoNi}_{2} \mathrm{~S}_{4} / \mathrm{rGO}-2$ electrode from AC coated on carbon cloth. The electrochemical performance of the device is detailed in Fig. S30. The specific capacitances of the $\mathrm{CoNi}_{2} \mathrm{~S}_{4} / \mathrm{rGO}-2 / / \mathrm{AC}$ flexible ASC device are as high as $46.3,43.6,37.2$, and $30.5 \mathrm{~F} \mathrm{~g}^{-1}$ at the current densities of $2,3,5$, and $10 \mathrm{~A} \mathrm{~g}^{-1}$, respectively. The flexible ASC device delivers a maximum energy density of $16.4 \mathrm{~W} \mathrm{~h} \mathrm{~kg}^{-1}$ at a power density of $1599 \mathrm{~W} \mathrm{~kg}^{-1}$. Thus, this method is feasible in the preparation of flexible and wearable supercapacitors, which brings great potential for wearable electronic technologies. The electrochemical performance of quasi-solidstate supercapacitor is inferior to that of liquid supercapacitor, which can be attributed to the relatively poor ionic conductivity of gel electrolyte compared with that of aqueous electrolyte. Moreover, gel electrolyte may have worse Ohmic contact with the electrode materials and current collectors than aqueous electrolyte, resulting in decreased diffusion rate of ions and enhanced chargetransfer resistance, and thus poor rate capability.

\section{CONCLUSIONS}

In this work, $2 \mathrm{D} \mathrm{CoNi}_{2} \mathrm{~S}_{4} / \mathrm{rGO}$ has been successfully constructed by a one-step pyrolysis approach. The asprepared $\mathrm{CoNi}_{2} \mathrm{~S}_{4} / \mathrm{rGO}$ hybrids with nanoparticles-onnanosheets structure, which is effective to provide a large number of active sites and shorten the electron/ion diffusion distance. Thus, the $\mathrm{CoNi}_{2} \mathrm{~S}_{4} / \mathrm{rGO}$ exhibits impressed specific capacitance of 1526 at $2 \mathrm{~A} \mathrm{~g}^{-1}$ as well as excellent rate performance. The fabricated ASC devices with $\mathrm{CoNi}_{2} \mathrm{~S}_{4} / \mathrm{rGO}$ as the positive electrode and $\mathrm{AC}$ as the negative electrode exhibits an energy density of $54.8 \mathrm{~W} \mathrm{~h} \mathrm{~kg}^{-1}$ at a power density of $798 \mathrm{~W} \mathrm{~kg}^{-1}$. Moreover, the $\mathrm{CoNi}_{2} \mathrm{~S}_{4} / \mathrm{rGO}$ electrode can also be used to fabricate flexible supercapacitors with remarkable performance. In addition, this simple one-step pyrolysis method was extended to fabricate various metal sulfide/
rGO hybrids. Therefore, this study provides a universal strategy to fabricate metal sulfide-based composites for energy conversion/storage.

\section{Received 1 April 2020; accepted 23 April 2020; published online 8 July 2020}

1 El-Kady MF, Strong V, Dubin S, et al. Laser scribing of highperformance and flexible graphene-based electrochemical capacitors. Science, 2012, 335: 1326-1330

2 Zhang YZ, Wang Y, Cheng T, et al. Printed supercapacitors: materials, printing and applications. Chem Soc Rev, 2019, 48: 32293264

3 Shin J, Seo JK, Yaylian R, et al. A review on mechanistic understanding of $\mathrm{MnO}_{2}$ in aqueous electrolyte for electrical energy storage systems. Int Mater Rev, 2019, : 1-32

4 Tan H, Feng Y, Rui X, et al. Metal chalcogenides: paving the way for high-performance sodium/potassium-ion batteries. Small Methods, 2020, 4: 1900563

5 Shao Y, El-Kady MF, Sun J, et al. Design and mechanisms of asymmetric supercapacitors. Chem Rev, 2018, 118: 9233-9280

6 Lukatskaya MR, Dunn B, Gogotsi Y. Multidimensional materials and device architectures for future hybrid energy storage. Nat Commun, 2016, 7: 12647

7 Yu XY, David Lou XW. Mixed metal sulfides for electrochemical energy storage and conversion. Adv Energy Mater, 2018, 8: 1701592

8 Geng P, Zheng S, Tang H, et al. Transition metal sulfides based on graphene for electrochemical energy storage. Adv Energy Mater, 2018, 8: 1703259

9 Yao B, Li M, Zhang J, et al. TiN paper for ultrafast-charging supercapacitors. Nano-Micro Lett, 2019, 12: 3

10 Huang J, Wei J, Xiao Y, et al. When Al-doped cobalt sulfide nanosheets meet nickel nanotube arrays: a highly efficient and stable cathode for asymmetric supercapacitors. ACS Nano, 2018, 12: 3030-3041

11 He W, Wang C, Li H, et al. Ultrathin and porous $\mathrm{Ni}_{3} \mathrm{~S}_{2} / \mathrm{CoNi}_{2} \mathrm{~S}_{4}$ 3D-network structure for superhigh energy density asymmetric supercapacitors. Adv Energy Mater, 2017, 7: 1700983

12 Huang J, Peng Z, Xiao Y, et al. Hierarchical nanosheets/walls structured carbon-coated porous vanadium nitride anodes enable wide-voltage-window aqueous asymmetric supercapacitors with high energy density. Adv Sci, 2019, 6: 1900550

13 Xiong T, Tan TL, Lu L, et al. Harmonizing energy and power density toward $2.7 \mathrm{~V}$ asymmetric aqueous supercapacitor. Adv Energy Mater, 2018, 8: 1702630

14 Song Y, Deng P, Qin Z, et al. A polyanionic molybdenophosphate anode for a $2.7 \mathrm{~V}$ aqueous pseudocapacitor. Nano Energy, 2019, 65: 104010

15 Peng Z, Gong L, Huang J, et al. Construction of facile ion and electron diffusion by hierarchical core-branch $\mathrm{Zn}$ substituted NiCo-S nanocomposite for high-performance asymmetric supercapacitors. Carbon, 2019, 153: 531-538

$16 \mathrm{Hu} \mathrm{H}$, Guan BY, Lou XWD. Construction of complex CoS hollow structures with enhanced electrochemical properties for hybrid supercapacitors. Chem, 2016, 1: 102-113

17 Li S, He W, Liu B, et al. One-step construction of three-dimensional nickel sulfide-embedded carbon matrix for sodium-ion batteries and hybrid capacitors. Energy Storage Mater, 2019, 25: 
636-643

18 Xiao J, Wan L, Yang S, et al. Design hierarchical electrodes with highly conductive $\mathrm{NiCo}_{2} \mathrm{~S}_{4}$ nanotube arrays grown on carbon fiber paper for high-performance pseudocapacitors. Nano Lett, 2014, 14: 831-838

19 Xiong X, Waller G, Ding D, et al. Controlled synthesis of $\mathrm{NiCo}_{2} \mathrm{~S}_{4}$ nanostructured arrays on carbon fiber paper for high-performance pseudocapacitors. Nano Energy, 2015, 16: 71-80

20 Huang J, Wei J, Xu Y, et al. A pinecone-inspired hierarchical vertically aligned nanosheet array electrode for high-performance asymmetric supercapacitors. J Mater Chem A, 2017, 5: 2334923360

21 Sahoo S, Rout CS. Facile electrochemical synthesis of porous manganese-cobalt-sulfide based ternary transition metal sulfide nanosheets architectures for high performance energy storage applications. Electrochim Acta, 2016, 220: 57-66

22 Tang J, Ge Y, Shen J, et al. Facile synthesis of $\mathrm{CuCo}_{2} \mathrm{~S}_{4}$ as a novel electrode material for ultrahigh supercapacitor performance. Chem Commun, 2016, 52: 1509-1512

23 Staszak-Jirkovský J, Malliakas CD, Lopes PP, et al. Design of active and stable Co-Mo-S $\mathrm{S}_{x}$ chalcogels as $\mathrm{pH}$-universal catalysts for the hydrogen evolution reaction. Nat Mater, 2016, 15: 197-203

24 Wang Y, Huang J, Xiao Y, et al. Hierarchical nickel cobalt sulfide nanosheet on MOF-derived carbon nanowall arrays with remarkable supercapacitive performance. Carbon, 2019, 147: 146-153

25 Gao YP, Huang KJ. $\mathrm{NiCo}_{2} \mathrm{~S}_{4}$ materials for supercapacitor applications. Chem Asian J, 2017, 12: 1969-1984

26 Lee HS, Gund GS, Park HS. Controlled growth and interaction of $\mathrm{NiCo}_{2} \mathrm{~S}_{4}$ on conductive substrate for enhanced electrochemical performance. J Power Sources, 2020, 451: 227763

27 Huang Y, Ge S, Chen X, et al. Hierarchical $\mathrm{FeCo}_{2} \mathrm{~S}_{4} @ \mathrm{FeNi}_{2} \mathrm{~S}_{4}$ core/ shell nanostructures on $\mathrm{Ni}$ foam for high-performance supercapacitors. Chem Eur J, 2019, 25: 14117-14122

28 Chen W, Xia C, Alshareef HN. One-step electrodeposited nickel cobalt sulfide nanosheet arrays for high-performance asymmetric supercapacitors. ACS Nano, 2014, 8: 9531-9541

29 Beka LG, Li X, Liu W. Nickel cobalt sulfide core/shell structure on 3D graphene for supercapacitor application. Sci Rep, 2017, 7: 2105

30 Zhu Y, Wu Z, Jing $\mathrm{M}$, et al. Mesoporous $\mathrm{NiCo}_{2} \mathrm{~S}_{4}$ nanoparticles as high-performance electrode materials for supercapacitors. J Power Sources, 2015, 273: 584-590

31 Cao X, He J, Li $\mathrm{H}$, et al. $\mathrm{CoNi}_{2} \mathrm{~S}_{4}$ nanoparticle/carbon nanotube sponge cathode with ultrahigh capacitance for highly compressible asymmetric supercapacitor. Small, 2018, 14: 1800998

32 Xiao Y, Su D, Wang X, et al. In situ growth of ultradispersed $\mathrm{NiCo}_{2} \mathrm{~S}_{4}$ nanoparticles on graphene for asymmetric supercapacitors. Electrochim Acta, 2015, 176: 44-50

33 Peng $\mathrm{S}, \mathrm{Li} \mathrm{L}, \mathrm{Li} \mathrm{C}$, et al. In situ growth of $\mathrm{NiCo}_{2} \mathrm{~S}_{4}$ nanosheets on graphene for high-performance supercapacitors. Chem Commun, 2013, 49: 10178

34 Balamurugan J, Nguyen TT, Aravindan V, et al. Flexible solid-state asymmetric supercapacitors based on nitrogen-doped graphene encapsulated ternary metal-nitrides with ultralong cycle life. Adv Funct Mater, 2018, 28: 1804663

35 AbdelHamid AA, Yu Y, Yang J, et al. Generalized synthesis of metal oxide nanosheets and their application as Li-ion battery anodes. Adv Mater, 2017, 29: 1701427

36 Dreyer DR, Park S, Bielawski CW, et al. The chemistry of graphene oxide. Chem Soc Rev, 2010, 39: 228-240

37 Ma Y, Chang H, Zhang M, et al. Graphene-based materials for lithium-ion hybrid supercapacitors. Adv Mater, 2015, 27: 52965308

38 Yang J, Yu C, Fan X, et al. Electroactive edge site-enriched nickelcobalt sulfide into graphene frameworks for high-performance asymmetric supercapacitors. Energy Environ Sci, 2016, 9: 1299_ 1307

39 Jing C, Guo X, Xia L, et al. Morphologically confined hybridization of tiny $\mathrm{CoNi}_{2} \mathrm{~S}_{4}$ nanosheets into $\mathrm{S}, \mathrm{P}$ co-doped graphene leading to enhanced pseudocapacitance and rate capability. Chem Eng J, 2020, 379: 122305

40 Sarkar D, Das D, Das S, et al. Expanding interlayer spacing in $\mathrm{MoS}_{2}$ for realizing an advanced supercapacitor. ACS Energy Lett, 2019, 4: 1602-1609

41 Sahoo R, Pham DT, Lee $\mathrm{TH}$, et al. Redox-driven route for widening voltage window in asymmetric supercapacitor. ACS Nano, 2018, 12: 8494-8505

42 Zhang C, Cai X, Qian Y, et al. Electrochemically synthesis of nickel cobalt sulfide for high-performance flexible asymmetric supercapacitors. Adv Sci, 2018, 5: 1700375

43 Jiang $\mathrm{D}$, Liang $\mathrm{H}$, Yang $\mathrm{W}$, et al. Screen-printable films of graphene/ $\mathrm{CoS}_{2} / \mathrm{Ni}_{3} \mathrm{~S}_{4}$ composites for the fabrication of flexible and arbitrary-shaped all-solid-state hybrid supercapacitors. Carbon, 2019, 146: 557-567

44 Dai S, Zhang Z, Xu J, et al. In situ Raman study of nickel bicarbonate for high-performance energy storage device. Nano Energy, 2019, 64: 103919

45 Wan C, Jiao Y, Liang D, et al. A geologic architecture systeminspired micro-/nano-heterostructure design for high-performance energy storage. Adv Energy Mater, 2018, 8: 1802388

46 Tang $\mathrm{X}$, Zhu C, Cheng D, et al. Architectured leaf-inspired $\mathrm{Ni}_{0.33} \mathrm{Co}_{0.66} \mathrm{~S}_{2} /$ graphene aerogels via $3 \mathrm{D}$ printing for high-performance energy storage. Adv Funct Mater, 2018, 28: 1805057

47 Yuan K, Lützenkirchen-Hecht D, Li L, et al. Boosting oxygen reduction of single iron active sites via geometric and electronic engineering: nitrogen and phosphorus dual coordination. J Am Chem Soc, 2020, 142: 2404-2412

48 Li Y, Cao R, Li L, et al. Simultaneously integrating single atomic cobalt sites and $\mathrm{Co}_{9} \mathrm{~S}_{8}$ nanoparticles into hollow carbon nanotubes as trifunctional electrocatalysts for $\mathrm{Zn}$-air batteries to drive water splitting. Small, 2020, 16: 1906735

49 Li L, Li Y, Xiao $\mathrm{Y}$, et al. $\mathrm{Fe}_{3} \mathrm{O}_{4}$-encapsulating $\mathrm{N}$-doped porous carbon materials as efficient oxygen reduction reaction electrocatalysts for Zn-air batteries. Chem Commun, 2019, 55: 7538-7541

50 Han P, Cheng M, Luo D, et al. Selective etching of C-N bonds for preparation of porous carbon with ultrahigh specific surface area and superior capacitive performance. Energy Storage Mater, 2020, 24: 486-494

51 Ramu M, Chellan JR, Goli N, et al. A self-branched lamination of hierarchical patronite nanoarchitectures on carbon fiber cloth as novel electrode for ionic liquid electrolyte-based high energy density supercapacitors. Adv Funct Mater, 2019, 30: 1906586

52 Yang S, Liu Y, Hao Y, et al. Oxygen-vacancy abundant ultrafine $\mathrm{Co}_{3} \mathrm{O}_{4}$ /graphene composites for high-rate supercapacitor electrodes. Adv Sci, 2018, 5: 1700659

$53 \mathrm{Wu} \mathrm{P}$, Cheng $\mathrm{S}$, Yao $\mathrm{M}$, et al. A low-cost, self-standing $\mathrm{NiCo}_{2} \mathrm{O}_{4} @ \mathrm{CNT} / \mathrm{CNT}$ multilayer electrode for flexible asymmetric solid-state supercapacitors. Adv Funct Mater, 2017, 27: 1702160

54 Guo Y, Wu C, Li NW, et al. Formation of Co-Mn mixed oxide double-shelled hollow spheres as advanced electrodes for hybrid supercapacitors. J Mater Chem A, 2019, 7: 25247-25253 
55 Yang L, Lu X, Wang S, et al. Designed synthesis of nickel-cobaltbased electrode materials for high-performance solid-state hybrid supercapacitors. Nanoscale, 2020, 12: 1921-1938

Acknowledgements This work was financially supported by the National Natural Science Foundation of China (21704038 and 51763018), the National Natural Science Foundation of China (NSFC)-German Research Foundation (DFG) Joint Research Project (51761135114), the Natural Science Foundation of Jiangxi Province (20192BCB23001, 2018ACB21021 and 20171ACB21009), China Postdoctoral Science Foundation (2018M632599), and the National Postdoctoral Program for Innovative Talents (BX201700112).

Author contributions Chen $\mathrm{Y}$ and Yuan $\mathrm{K}$ conceived and designed the experiments. Zhang K, Wei Y, Huang J, Xiao Y, Yang W and Hu T conducted the experiments, analyzed the data and wrote the manuscript. Chen Y and Yuan K supervised the project. All the authors participated in the discussions of the research.

Conflict of interest The authors declare no conflict of interest.

Supplementary information Supporting data are available in the online version of the paper.

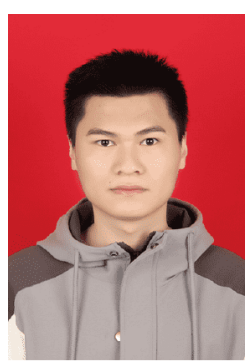

Kaiyang Zhang received his BSc degree from Xinjiang Normal University in 2018. He is currently a master candidate in the Institute of Polymers and Energy Chemistry (IPEC), Nanchang University. His research interests mainly focus on supercapacitors.

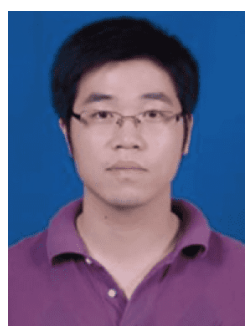

Kai Yuan received his first $\mathrm{PhD}$ from Nanchang University in 2016 under the supervision of Prof. Yiwang Chen. In 2014, he joined professor Ullrich Scherf's group at the University of Wuppertal in Germany, where he obtained his second $\mathrm{PhD}$ (summa cum laude) in 2017. Then, he was appointed as professor of chemistry at Nanchang University. His current scientific interests include graphene, porous polymer networks, twodimensional materials, carbon nanomaterials and the corresponding hybrids for electronic and energy-related applications.

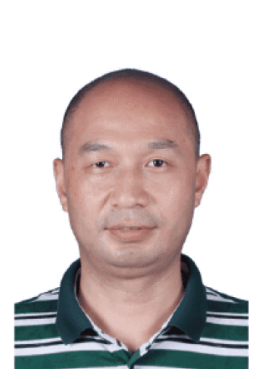

Yiwang Chen received his $\mathrm{PhD}$ from Peking University in 1999 and conducted his postdoctoral work at Johannes Gutenberg-Universität Mainz and Philipps-Universität Marburg in Germany as awarded an Alexander von Humboldt fellowship. He became a full professor at Nanchang University since 2004. His research interests include solution process and printing of polymer/perovskite solar cells, wet printing of transparent electrodes, supercapacitors, electrocatalysis for zinc-air batteries and direct methanol fuel cells, and intelligent organosilicone elastomer.

\section{一种通用的一步原位合成策略制备金属硫化物/ 还原氧化石墨烯纳米片用于高性能超级电容器}

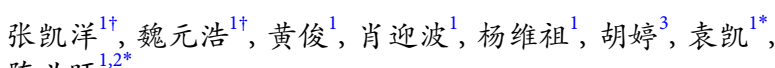
陈义旺 ${ }^{1,}$

摘要 金属硫化物在超级电容器领域具有良好的应用前景, 但缓慢 的反应动力学抑制了其电化学性能. 增加电化学表面积并与碳材 料结合可以改善其电化学性能. 然而, 寻求一种简单通用的方法制 备金属硫化物和导电碳的复合材料仍具有挑战性. 本文设计了一 种简单的一步热解法, 在温和的条件下将硫化钴镍 $\left(\mathrm{CoNi}_{2} \mathrm{~S}_{4}\right)$ 原位 生长在还原氧化石墨烯 $(\mathrm{rGO})$ 纳米片上. 制备的硫化镍钴/还原氧 化石墨烯 $\left(\mathrm{CoNi}_{2} \mathrm{~S}_{4} / \mathrm{rGO}\right)$ 材料具备纳米片结构, 可以提供大量的活 性位点, 有效地缩短电子/离子的扩散路径. 得益于这些优点, 所制 备的 $\mathrm{CoNi}_{2} \mathrm{~S}_{4} / \mathrm{rGO}$ 电极材料在电流密度分别为 2 和 $20 \mathrm{~A} \mathrm{~g}^{-1}$ 时具有 1526 和 $988 \mathrm{~F} \mathrm{~g}^{-1}$ 的高比电容. 基于 $\mathrm{CoNi}_{2} \mathrm{~S}_{4} / \mathrm{rGO}$ 的非对称超级电容 器工作电压窗口为 $1.6 \mathrm{~V}$, 在功率密度为 $798 \mathrm{~W} \mathrm{~kg}^{-1}$ 时能量密度高达 $54.8 \mathrm{~W} \mathrm{~h} \mathrm{~kg}^{-1}$. 在 $3 \mathrm{~A} \mathrm{~g}^{-1}$ 下循环 8000 次后, 其容量保持率为 $93.7 \%$. 利用该方法可获得一系列金属硫化物/rGO复合材料, 此通用策略 可推广应用于各种能源器件电极材料的制备. 